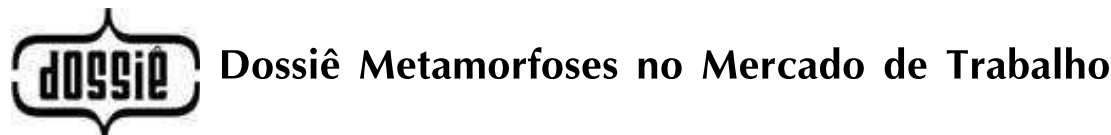

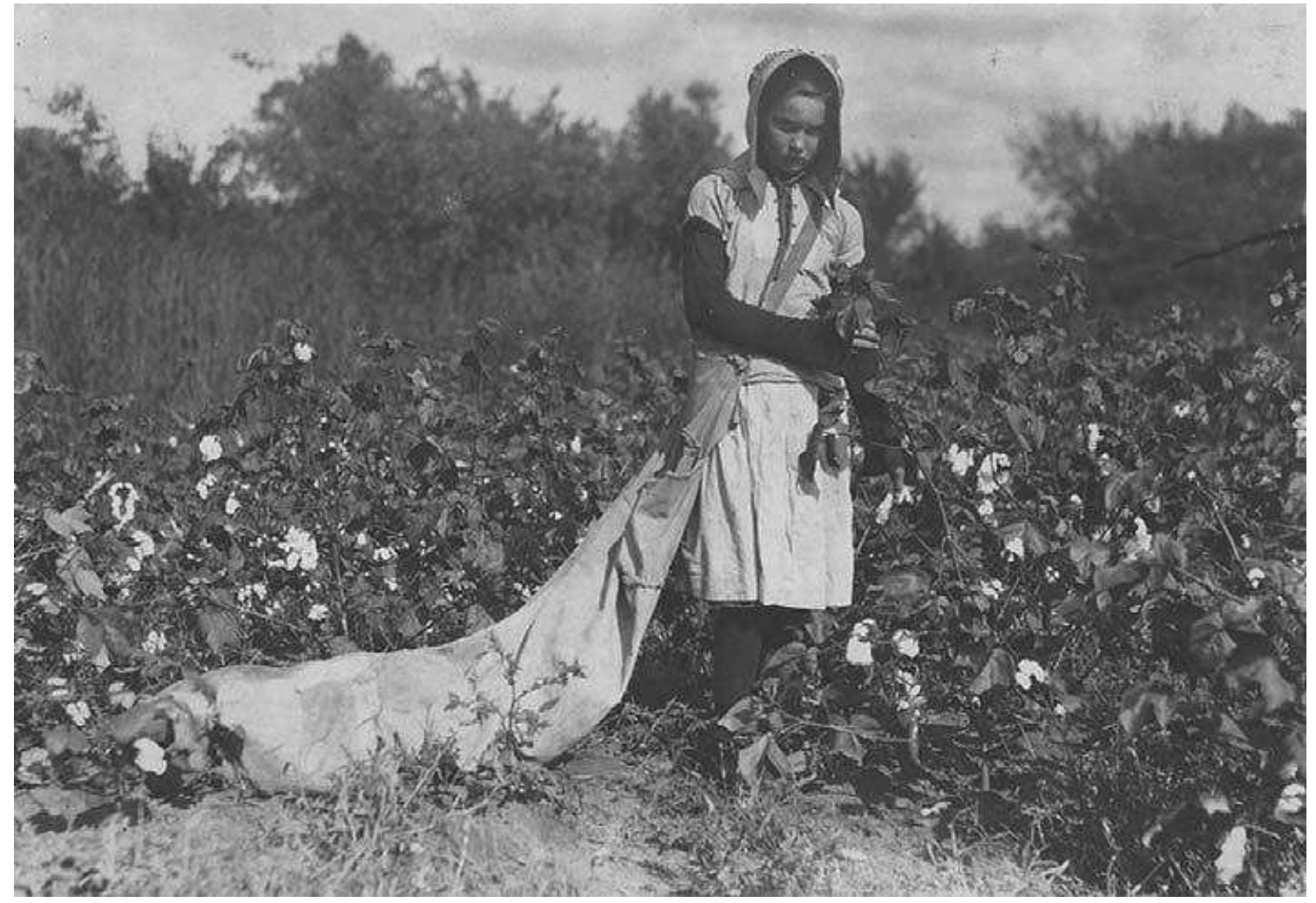

Callie Campbell, Lewis Hine (1874-1940), Oklahoma, EUA. 


\title{
O emprego no Brasil urbano nos anos 2000: recuperação e reconfiguração*
}

\author{
Employment in urban Brazil in the 2000s: \\ recovery and reconfiguration
}

Ângela Maria Carvalho Borges*

\begin{abstract}
Resumo: $O$ trabalho investiga o comportamento e o perfil do emprego no mercado de trabalho do Brasil urbano nos anos 2000, considerando as diferenças regionais. Explorando os microdados da PNAD, após traçar um rápido panorama do mercado de trabalho neste período, se analisa o perfil da expansão dos postos de trabalho assalariados e do emprego no setor público depois de 2003. Discute essa recuperação como uma mudança que não se limita a um simples efeito da melhoria do quadro macroeconômico, mas que também embute um processo de reconfiguração deste segmento do mercado de trabalho brasileiro.
\end{abstract}

Palavras-chave: mercado de trabalho; emprego; Brasil urbano.

\begin{abstract}
This paper studies the behavior and profile of employment in the labor market of urban Brazil in the 2000s, considering the regional differences. Exploring PNAD microdata, after sketching a brief panorama of the labor market in this period, we analyze the profile of the expansion of paid jobs and employment in the public sector after 2003, and discuss this recovery as a change that is not limited to the simple effect of the improved macro economics conditions, but which also encompasses a process of reconfiguration of the segment of this Brazilian labor market.
\end{abstract}

Keywords: labor market; jobs; urban Brazil.

\footnotetext{
* Uma versão preliminar deste trabalho foi apresentada no XV Congresso Brasileiro de Sociologia, SBS, Curitiba, jul. 2011.

** Doutora em Ciências Sociais, professora e coordenadora do Programa de Pós-Graduação em Políticas Sociais e Cidadania da Universidade Católica de Salvador (UCSAL), pesquisadora associada do CRH/UFBA e do Núcleo de Estudos do Trabalho (NET). Correspondência: Campus da Federação, Avenida Cardeal da Silva, 205, Federação, Salvador/BA. E-mail: <angelborges@ uol.com.br>.
} 


\section{Introdução}

A crise que se abateu sobre o mercado de trabalho brasileiro nos anos 1990, de natureza e dimensão inéditas, resultou da confluência de dois processos inter-relacionados: o esgotamento do modelo de desenvolvimento seguido pelo país no pós-guerra e as transformações estruturais do capitalismo contemporâneo sob a hegemonia do paradigma teórico-ideológico neoliberal, que orientou as políticas mais relevantes para os desdobramentos desses processos.

O novo paradigma produtivo, já hegemônico no plano mundial, foi rapidamente introduzido no país. As políticas emanadas das recomendações do Fundo Monetário Internacional (FMI) foram postas em prática pelos sucessivos governos, resultando numa completa reconfiguração da economia brasileira. Também redundou em uma forte alteração na distribuição funcional da renda, a favor das empresas e do governo (que usa os novos recursos para pagamento dos juros da dívida) em detrimento do trabalho, cuja participação no valor agregado caiu de $37,5 \%$ para $32,8 \%$, se computadas as contribuições sociais, e de $32 \%$ para $26 \%$, se estas são excluídas.

O ponto de inflexão foi o ano de 1989, quando a vitória das forças que àquela altura representavam - e/ou cujos interesses eram os mesmos dos que comandam a globalização - viabilizou a guinada na política econômica e no caráter do Estado. A partir de então, voltou-se prioritariamente para otimizar as condições de rentabilidade do capital em nível nacional, adequando a economia brasileira às novas exigências do processo e acumulação. Sob seu comando, o crescimento econômico e o bem-estar da população tornaram-se excludentes e "o mercado" se impôs absoluto, na determinação de todas as possibilidades.

A abertura foi feita de forma indiscriminada, sem uma estratégia que preparasse o tecido econômico e institucional de uma economia fechada para uma exposição em grau máximo à concorrência internacional e para os ajustes decorrentes, dentre os quais a desregulamentação dos mercados, inclusive do mercado de trabalho. A desregulamentação do mercado de trabalho foi justificada pela suposta inadequação aos novos tempos da regulação das relações de trabalho vigente no país, consideradas obstáculos à competitividade da economia brasileira e, logo, à geração de novos postos de trabalho.

Coerente com esse diagnóstico, um conjunto de mudanças legais e de políticas públicas foi implementado ao longo da década de 1990, dentre elas: mudanças na legislação trabalhista destacando-se, particularmente, a introdução de novos tipos de contrato de trabalho mais flexíveis e com menos direitos (num mercado de trabalho em que as empresas já têm ampla liberdade para contratar, demitir e remunerar); a revogação da política salarial, remetendo à possibilidade de recomposição e de ganhos salariais à 
negociação direta entre patrões e empregados (num contexto de desemprego elevado e crescente); a flexibilização da jornada de trabalho e, principalmente, a redução do papel fiscalizador do Estado, facilitando a burla da lei por parte das empresas.

Os impactos da reestruturação produtiva e da desregulamentação neoliberal dos anos 1990 sobre o mercado de trabalho brasileiro foram devastadores. O principal e mais visível deles foi o descolamento das curvas de produção e de emprego. Ao contrário dos anos 1980, na década de 1990 o desemprego não cedeu quando a economia se recuperou. Os empregos destruídos não voltaram mais, inaugurando no país o fenômeno do desemprego aberto elevado, de longa duração e estrutural, porque decorrente de mudanças igualmente estruturais.

Além do desemprego, a reestruturação produtiva comandada pelas políticas neoliberais resultou em mudanças na estrutura do emprego urbano, bem assim, nos padrões de contratação e uso da força de trabalho. Observou-se um expressivo aumento da heterogeneidade no mercado de trabalho, o desassalariamento acompanhado da queda absoluta e relativa do emprego com carteira assinada (o emprego protegido), crescimento do emprego precário e do trabalho por conta própria.

No plano ideológico, a interpretação hegemônica colocou tais processos como tendências inexoráveis, associadas a novas perspectivas, como o empreendedorismo e a busca contínua da empregabilidade através da qualificação contínua, apoiada por políticas públicas, mas, em última instância, uma responsabilidade dos próprios trabalhadores.

No entanto, a maior parte dos indicadores, pesquisas e estudos, quantitativos e qualitativos que trataram do mercado de trabalho e das relações de trabalho nos últimos anos negam esta interpretação. Assim, passada a fase mais aguda da reestruturação, marcada por uma sequência de crises no plano mundial, a economia brasileira voltou a crescer a taxas expressivas - sobretudo na segunda metade dos anos 2000 - e os níveis de ocupação se recuperaram, enxugando parte do excedente de trabalhadores e derrubando as taxas de desemprego que, não obstante, ainda permaneceram num patamar extremamente elevado. Segundo Pochmann (2010), pela primeira vez em 40 anos, viu-se, no Brasil, o crescimento do PIB acompanhado do crescimento da renda per capita e com redução da desigualdade de rendimentos.

Além disto, contrariando a expectativa de uma redução do assalariamento acompanhada do crescimento expressivo do trabalho por contaprópria - re-significado como uma opção de inserção virtuosa no mercado de trabalho - este se manteve num patamar que, na maior parte dos mercados metropolitanos, não ultrapassa os $25 \%$ dos ocupados. Do mesmo modo, negando os argumentos utilizados para defender a desregulamentação das relações de trabalho, o emprego minimamente protegido, "com carteira assinada", registrou crescimento vigoroso a partir de meados da década de 
2000. A permanência de taxas de desemprego ainda elevadas entre os mais escolarizados (sobretudo aqueles que têm apenas o ensino médio) constituise em um indicador inquestionável da fragilidade do discurso da empregabilidade.

Neste estudo, com base em um conjunto de indicadores quantitativos construídos com dados da Pesquisa Nacional por Amostra de Domicílios (PNAD) e em estudos qualitativos acumulados nos últimos dez anos, discute-se o caráter das transformações ocorridas nos mercados de trabalho metropolitanos entre 2002 - 2009, que reverteram tendências (ao menos por um período) contrariando análises e idéias dominantes nos anos 1990. Considera-se aqui que o ciclo expansivo iniciado na primeira década do século XXI não tem a sua continuidade assegurada e que os seus efeitos positivos sobre o mercado de trabalho podem ser parcial ou totalmente revertidos se a crise global acirrar a vulnerabilidade externa da economia brasileira como, aliás, observou-se em 2009. (GONÇALVES, 2011).

O artigo divide-se em três partes: esta Introdução, Desempenho dos mercados de trabalho metropolitanos, subdividida em quatro seções Atividade, ocupação e desocupação; Formas de inserção, Distribuição setorial da ocupação e Rendimentos - e as Considerações finais.

\section{Desempenho dos mercados de trabalho metropolitanos}

As nove regiões metropolitanas estudadas concentravam, em 2009, 30,5\% da População Economicamente Ativa (PEA): e 29\% dos ocupados do país. Trata-se dos espaços econômicos mais estruturados das respectivas regiões, cujos mercados de trabalho apresentam tanto grandes concentrações de postos de trabalho qualificados e protegidos como de ocupações mais simples, precárias e mal remuneradas.

Em consequência das diferentes posições ocupadas por cada região metropolitana nas divisões inter-regional e internacional do trabalho, o universo dos mercados de trabalho metropolitanos é bastante heterogêneo, tanto em termos da magnitude - em 2009, a população economicamente ativa variava de 1.049 mil (Região Metropolitana de Belém) a 10.744 miIhões (São Paulo) - quanto em relação ao grau de estruturação, composição setorial, ao perfil ocupacional e aos níveis médios de desemprego. No Sudeste, região que comanda o processo de acumulação, estão os dois maiores e mais estruturados mercados de trabalho do país (São Paulo, com 9,5 milhões de ocupados e Rio de Janeiro, com 5,3 milhões, em 2009). Já no Nordeste, os mercados de trabalho metropolitanos, além de bem menores (sendo o maior o da Região Metropolitana de Salvador, com 1,9 milhões de ocupados) apresentam proporções mais elevadas de postos de trabalho de baixa produtividade e precários. 


\subsection{Atividade, ocupação e desocupação}

Entre 2002 e 2009, no conjunto do país, o número de ocupados cresceu mais $(2 \%$ a.a.) do que a PEA $(1,9 \%$ a.a.) e do que a População em Idade Ativa (PIA) (1,7 a.a). Ou seja, embora a pressão demográfica sobre o mercado de trabalho tenha se mantido com a elevação da taxa de atividade (de $61,3 \%$ para $62,1 \%$ ) provocada pelo aumento do peso dos grupos etários que apresentam maior participação no mercado de trabalho e pelo dinamismo da economia que atrai as pessoas antes inativas. Também a demanda por trabalho cresceu vigorosamente, levando à expansão da ocupação e à queda das taxas de desemprego, embora elas ainda fossem bastante elevadas no final do período $(8,3 \%)$.

O agregado das regiões metropolitanas apresenta tendência semeIhante: a PIA cresceu a 1,4\% a.a. no período considerado e a PEA a 1,8\%. A taxa de atividade subiu de 60,5\% em 2002 para 62\% em 2009, mas foram observadas diferenças importantes entre os mercados de trabalho metropolitanos, com os ritmos de expansão da PIA e da PEA maiores nas Regiões Metropolitanas (RMs) do Norte e Nordeste do que nas do Sudeste. Os mercados de trabalho das RMs de São Paulo e do Rio de Janeiro, mesmo tendo reduzido um pouco o seu peso no conjunto metropolitano, ainda respondiam, em 2009, pela maior parcela da PEA (54,5\%).

Quanto à ocupação, na média metropolitana o estoque de ocupados cresceu $2,1 \%$ ao ano e a taxa de ocupação, calculada com relação a PIA, cresceu em todas as Regiões Metropolitanas (com a exceção da RM Recife). Os maiores incrementos foram registrados em Salvador (6 pontos percentuais), Fortaleza e Rio de Janeiro (cerca de 4 pontos), refletindo os efeitos territorialmente diferenciados da retomada do crescimento sobre os mercados de trabalho. Com esta expansão da ocupação, em 2009, apenas na RM Recife a proporção de pessoas ocupadas não ultrapassava os 50\% da PIA, girando este percentual em torno de $60 \%$ em Curitiba $(61,3 \%)$, Belo Horizonte $(59,9 \%$ ) e Salvador $(58,1 \%)$, o que sinaliza uma situação bastante favorável em termos de taxa de dependência.

No que se refere ao desemprego, o conjunto dos mercados de trabalho metropolitanos apresentou um desempenho melhor do que a média nacional, com a redução absoluta no estoque de desempregados e queda da sua participação neste estoque de 43,5\% para 38\% entre 2002 e 2009. Observou-se, porém, a exceção da Região Metropolitana Recife, a única região a registrar crescimento no número de desempregados.

A taxa de desemprego metropolitana média, apesar de decrescente (de $13 \%$ para $10,5 \%$ ), ainda se manteve elevada, embora, também neste caso, as diferenças sejam marcantes, com as taxas da RM Salvador $(14,2)$ e da RM Recife $(15,9)$, correspondendo a quase o dobro da taxa da RM Porto Alegre $(7,6)$ e da RM Curitiba $(7,4)$. Lembra-se, no entanto, que em decorrência das diferenças de tamanho dos mercados de trabalho, as taxas mais baixas das regiões mais desenvolvidas em algumas situações correspondem 
a contingentes muito mais numerosos de desempregados. Assim, por exemplo, em 2009, encontravam-se no mercado de trabalho a RM São Paulo cuja taxa de desocupação era de 11,1\% - 37,2\% dos desempregados metropolitanos e 14,1\% dos desempregados do país.

A taxa de desemprego dos mercados de trabalho metropolitanos, em 2009, era de 10\% e correspondia a cerca de 3,2 milhões de desempregados, o que mostra os limites da recuperação em curso e sua repercussão sobre o grau de vulnerabilidade das populações metropolitanas, acentuado na década anterior, apesar da criação de novos postos de trabalho e dos ganhos de renda (sobretudo da maioria mais pobre). Tal persistência do desemprego deixa claro que as economias metropolitanas ainda são incapazes de incorporar a oferta de mão de obra disponível e também sinaliza para a fragilidade da inserção recente no mercado de trabalho. A permanência de excedentes desta magnitude sustenta a acentuada rotatividade da mão de obra que caracteriza o mercado de trabalho brasileiro, mantendo elevada a exposição dos trabalhadores, e das suas famílias, aos riscos do mercado de trabalho, entre os quais a perda de rendimentos, fator que contribui para a oscilação da renda familiar.

Três dimensões devem ser consideradas neste panorama da atividade, ocupação e desocupação nos mercados de trabalho metropolitanos: o gênero, a idade e escolaridade dos trabalhadores, dimensões que trouxeram mudanças importantes no perfil da oferta de trabalho entre 2002 e 2009. Ocorreu uma redução no peso relativo dos mais jovens, em consequência, sobretudo, de mudanças na estrutura etária da população e verificou-se a continuidade de dois processos em curso desde os anos 80 do século XX: a participação crescente das mulheres no mercado de trabalho e a elevação contínua da escolaridade da população como um todo e da população economicamente ativa, em particular.

A presença feminina nos mercados de trabalho metropolitanos evoluiu de $44,6 \%$ para $46,5 \%$ da PEA, e de $43,2 \%$ para $45,1 \%$ dos ocupados, entre 2002 e 2009. Embora mais acentuado nas áreas metropolitanas, este é um fenômeno de abrangência nacional - na média do país, em 2009, as mulheres já representavam 43,9\% da PEA e 42,6\% dos ocupados. Mas essa pressão feminina sobre o mercado de trabalho, mesmo em um período de expansão, não resultou apenas no aumento do número de mulheres ocupadas, pois elas também aumentam a sua representação no estoque de desempregados (de 54,4\% em 2002 para 59\% em 2009), um indicador da persistência das desigualdades de oportunidade entre homens e mulheres nos mercados de trabalho metropolitanos.

Quanto à idade, no conjunto das RMs a participação na PEA da população com menos de 20 anos, que já estava abaixo de $10 \%$ no início do período analisado, tornou-se ainda menor em 2009 (7,2\%) e no universo dos ocupados, esses trabalhadores passaram de $11 \%$ para $8 \%$ do total. Esta redução da participação de crianças, adolescentes e jovens na oferta de 
força de trabalho resulta de vários processos: o demográfico, isto é, redução do tamanho das coortes mais jovens; a elevação do tempo de frequência à escola, viabilizada pela redução do número de filhos, pela elevação dos rendimentos de grande parte das famílias mais pobres e pela ampliação das oportunidades educacionais para as novas gerações, que têm maiores chances de alcançar o ensino médio e o grau universitário. Ao lado destes fatores, que carregam um sinal positivo, contribuem também para a menor participação desses segmentos na PEA e no universo dos ocupados, em especial dos jovens com mais de 17 anos, fatores associados à situação de vulnerabilidade social dos segmentos mais pobres da população e que têm mantido parcelas não desprezíveis de jovens distantes dos dois principais integradores: a escola e o trabalho.

Por fim, quanto às mudanças no perfil etário dos trabalhadores, embora os adultos entre 20 e 49 anos continuassem a representar a maior parcela da PEA metropolitana - 75\% em 2009 - há de se observar o crescimento do contingente de pessoas com 50 anos ou mais na PEA (15,1\% para $18,9 \%$ ) e de $18,3 \%$ para $22 \%$ no contingente de ocupados, revelando a repercussão do envelhecimento da população no mercado de trabalho, mas, provavelmente também, o valor atribuído à experiência em alguns setores de atividade e ocupações. Além disso, parte dos trabalhadores mais velhos vêm se beneficiando da escassez localizada de mão de obra qualificada e com experiência.

Considerando agora a variável "escolaridade" vê-se que entre 2002 e 2009, enquanto a parcela da PEA com menor número de anos de estudo registrou redução absoluta, aqueles com escolaridade superior ao ensino médio elevaram a sua participação de $41,5 \%$ para $53,8 \%$ nesses sete anos. Desta forma passaram a constituir mais da metade da oferta de trabalhadores nos mercados de trabalho metropolitanos, percentual que é ainda mais elevado quando sopesados apenas os trabalhadores mais jovens que estão entrando no mercado de trabalho.

Tais ganhos de escolaridade da oferta foram acompanhados pelo lado da demanda, que se tornou cada vez mais seletiva, resultando no aumento da participação dos que tinham pelo menos o diploma do ensino médio - de $42,5 \%$ para $54,5 \%$ do total de ocupados e de $11,9 \%$ para $14,7 \%$ entre a parcela com diploma universitário. No conjunto das regiões metropolitanas, quase todo o incremento da ocupação ocorrido entre 2002 e 2009 correspondeu a trabalhadores com 11 anos ou mais de estudo, ficando os que tinham nível universitário com mais de 1/4 das vagas criadas neste período.

O aumento da participação dos mais escolarizados nos mercados de trabalho metropolitanos foi generalizado, mas, em 2009, o percentual da PIA com no mínimo o ensino médio variava de 35\% na RM Belém e na RM Fortaleza a 44\% na RM São Paulo. No Nordeste, destacava-se a RM Salvador com 41,4\% da PIA nessa faixa de escolaridade em 2009. Também 
entre os ocupados os percentuais dos que tinham diploma de ensino médio, ou mais, variam entre as regiões, seguindo de perto a hierarquia da PIA, isto é, as RMs que apresentam os percentuais mais elevados da população nessa faixa de escolaridade são também as que apresentam maiores proporções de ocupados mais escolarizados. Isto parece indicar que a mudança do perfil de escolaridade dos ocupados deriva mais da mudança no perfil dos ofertantes de trabalho, isto é, dos trabalhadores, do que das mudanças na demanda dos empregadores. Ainda que as exigências de maior qualificação para uma parte dos novos postos de trabalho sejam verdadeiras e que um maior número de anos de estudo seja cada vez mais relevante para o acesso às diversas posições no mercado de trabalho, inclusive o trabalho doméstico.

A importância dos diplomas para o acesso a um posto de trabalho fica ainda mais evidente em se tratando dos empregados com carteira. Neste universo, considerando o conjunto dos mercados de trabalho metropolitanos, a presença dos trabalhadores com maior escolarização é mais marcante, com nada menos do que $65 \%$ dos empregados com escolaridade correspondente ao ensino médio completo ou mais em 2009 e cerca de 15\% com diploma de nível superior. Tais proporções confirmam a crescente exigência dos empregadores que utilizam a posse de diplomas como critério de seleção, mesmo para os postos de trabalho mais simples, beneficiandose de uma oferta de trabalhadores mais escolarizados sem assegurar, contudo, a retribuição por eles esperada.

Como se depreende das informações sobre os rendimentos destes trabalhadores, comentadas mais à frente, a influência da crescente elevação dos níveis de escolaridade na determinação da composição da população ocupada fica evidente quando se observa que são exatamente os mercados de trabalho das metrópoles nordestinas, cujas economias são menos dinâmicas e apresentam estruturas ocupacionais com maiores proporções de postos de trabalho de baixa produtividade, que são encontrados os percentuais mais elevados de empregos formais ocupados por trabalhadores com 11 anos ou mais de estudo e não as RMs do Sudeste/Sul, como seria de se esperar tendo em vista as estruturas produtivas. Esses mercados de trabalho - em especial RM São Paulo, RM Rio de Janeiro e RM Curitiba - vão se destacar apenas nos percentuais de empregos formais para os portadores de diplomas de nível universitário.

Como já ressaltado em outros trabalhos (BORGES, 2003; 2011) a preferência dos empregadores pelos mais escolarizados não significa, no entanto, que aqueles que portam os diplomas do ensino médio e de nível superior tenham assegurado, como no passado, o acesso a um posto de trabalho. Pelo contrário, mesmo em um contexto de ampliação das oportunidades e de exigências crescentes de escolaridade como o atual, os trabaIhadores mais escolarizados das RMs (ensino médio ou mais) veem aumentar a sua participação no estoque de desempregados, a qual já correspondia, 
em 2009, a quase metade dele (48,6\%). E, mais que isto, no período coberto por este estudo, todo o incremento do número de desempregados foi formado por trabalhadores com pelo menos o diploma do ensino médio, uma vez que ocorreu redução absoluta dos contingentes de desempregados com menor escolaridade.

Em 2009, a taxa de desemprego mais elevada correspondia ao segmento que tinha entre 8 e 10 anos de estudo e a segunda exatamente aos que tinham concluído o ensino médio ou cursavam a universidade. A mais baixa era a dos que tinham o diploma de nível superior $(4,2 \% \mathrm{em}$ 2009), o que retrata o valor que ainda tem este diploma. Entre os desempregados, também em 2009, as maiores proporções de trabalhadores com escolaridade média ou superior eram encontradas nas Regiões Metropolitanas do Rio de Janeiro (52\%); Recife (49,5\%) e São Paulo e Curitiba $(49 \%)$.

Obviamente a crescente presença de trabalhadores mais escolarizados entre os desempregados é coerente com a redução da parcela da PEA das RMs com escolaridade mais baixa, mas também pode estar indicando a exclusão destes últimos dos mercados de trabalho metropolitanos. Além disto, podem ser levantadas duas outras hipóteses para explicar esta mudança no perfil dos desempregados. A de que o desemprego dos mais escolarizados esteja relacionado com o perfil rebaixado - em termos salariais e do tipo de ocupação - dos postos de trabalho, gerados na expansão dos anos 2000, os quais, não atendendo às expectativas dos mais qualificados, majoritariamente jovens, sequer seriam procurados pelos demandantes de emprego, cuja estrutura familiar lhes permite permanecer por mais tempo sem trabalhar.

Uma segunda hipótese remete à aparente contradição entre o desemprego dos escolarizados e o recorrente diagnóstico de que, após alguns poucos anos de crescimento econômico, a economia do país já enfrenta escassez de trabalhadores qualificados, constituindo um dos obstáculos à continuidade do atual ciclo expansivo. Tentativas de medir este déficit têm sido feitas (Instituto de Pesquisa Econômica Aplicada, 2011), mas o Brasil ainda não dispõe de indicadores confiáveis e atualizados sobre a demanda efetiva de qualificação por parte das empresas, capazes de melhor avaliar o fenômeno nas suas várias dimensões e de orientar uma política de qualificação de mão de obra. Certamente a escassez existe, mas parece ser localizada em termos geográfico, setorial e ocupacional e, provavelmente, decorre de múltiplos fatores: a baixa qualidade do ensino na maior parte dos estabelecimentos das redes pública e privada que não assegura aos diplomados a posse dos conhecimentos nem as competências e habilidades correspondentes ao diploma conquistado; a baixa eficácia do sistema de qualificação de mão de obra e o baixo investimento das empresas na qualificação dos seus empregados, além do previsível descolamento entre o perfil da oferta de vagas no sistema educacional - que condiciona as 
escolhas profissionais dos mais jovens - e a demanda das empresas no atual ciclo de expansão. Quanto a este ponto, ressalta o exemplo das áreas técnicas, em especial aquelas ligadas à engenharia e à construção civil: duas décadas de recessão/baixo crescimento esvaziaram os cursos destas áreas, estes cursos menos beneficiados pela expansão recente do ensino superior, puxada pelo setor privado e com investimentos orientados pelo custo/ maior retorno dos cursos.

\subsection{Formas de inserção}

Traduzindo o baixo grau de estruturação que marca o mercado de trabalho brasileiro em 2009 nas áreas metropolitanas - as mais estruturadas das suas respectivas regiões - o grau de assalariamento subiu de $62,6 \%$ para $65,8 \%$, como resultado da expansão acentuada dos postos de trabalho assalariados (empregados), que representaram $82,8 \%$ do incremento da ocupação no período. Trata-se de uma expansão provocada mais pela demanda, estimulada pelo crescimento da economia, do que pelo lado da oferta, que geralmente se materializa na forma de incremento das atividades por conta própria, não remuneradas, e nos pequenos negócios.

Como dito, todo o crescimento do estoque de empregados, na média das RMs, correspondeu a empregos formais - celetistas ou funcionários públicos. Esse resultado é mais favorável do que o encontrado para a média do país, que registrou aumento no número de empregos sem carteira, ainda que inferior ao crescimento da ocupação. No agregado das RMs, pelo contrário, o contingente de empregados em vínculos informais sofreu redução absoluta, sobretudo em função do comportamento dos mercados de trabalho das RMs de São Paulo, Belo Horizonte e Recife, uma vez que nas demais metrópoles, em especial Salvador e Fortaleza, essa forma de inserção continuou a registrar expansão significativa.

Em consequência, o grau de formalização do emprego nas RMs saltou de 73\% em 2002 para 78,1\% em 2009, restando, portanto, 21,9\% dos vínculos sem registro em carteira. Também as diferenças entre os mercados metropolitanos são visíveis no peso dos vínculos formais no incremento do número de ocupados do período estudado: 100\% em São Paulo e Recife. Ou seja, a expansão do emprego formal mais que compensou a destruição de postos de trabalho em outras posições na ocupação, como o emprego sem carteira, os não remunerados e os empregadores: $52,4 \% \mathrm{em}$ Belém e 57,4\% na RM Salvador. Porém, de uma maneira geral, o ritmo de expansão do emprego protegido foi mais acentuado nas RMs do nordeste do que no sudeste, o que revela o impacto regionalmente diferenciado do crescimento recente, embora coerente com o percentual mais baixo de formalização dos mercados de trabalho nordestinos. Apesar disso, os mercados de trabalho das metrópoles do Sudeste continuaram a apresentar um grau de estruturação mais elevado do que os demais em 2009. 
Em síntese, a expansão acentuada do emprego formal é uma das principais características da recuperação do dinamismo do mercado de trabalho brasileiro nos anos 2000 e veio reverter a tendência à informalização dos vínculos, marcante na década anterior. Neste sentido, os dados para os mercados de trabalho metropolitanos corroboram as principais conclusões da literatura mais recente e vão na contramão das opiniões que, nos anos 1990, anunciavam o "fim dos empregos", defendiam a inexorabilidade da retirada da regulação pública dos vínculos trabalhistas como condição sine qua non para a abertura de novas vagas e colocavam o contaproprismo e o empreendedorismo como as formas de trabalhar mais adequadas à nova etapa da acumulação.

A rápida expansão dos postos de trabalho formais mostra que a contratação de trabalhadores nesta forma e a regulação pública (para assegurar o mínimo de proteção social) não são incompatíveis com a busca da flexibilidade por parte das empresas. Pelo contrário, tal expansão no contexto de uma economia aberta e exposta a acirrada concorrência reafirma que, sobretudo após as mudanças introduzidas nos anos 1990, a regulação dos contratos de trabalho no Brasil é bastante flexível, não colocando barreiras à demissão imotivada, à polivalência ou à adequação da jornada de trabalho às necessidades do empregador.

É interessante registrar também que o crescimento expressivo e generalizado dos empregos formais não decorreu de automatismos do mercado - por exemplo, a rápida expansão da demanda levando ao enxugamento da oferta disponível e forçando os empregadores a melhorarem as condições de contratação - nem de uma pressão organizada da oferta, da luta política comandada pelos sindicatos, que permaneceram pouco ativos ao longo da década. Não por outra razão, os analistas do mercado de trabalho brasileiro têm concordado no reconhecimento de que a retomada do processo de estruturação do mercado de trabalho - com a expansão dos postos de trabalho que compõem o núcleo formal e protegido deste mercado, ainda que também tributário do crescimento econômico encontra a sua principal determinação na ação do Estado. Este, abandonando a postura pró-desregulamentação dos anos 1990, assumiu um papel mais ativo como garantidor da legislação trabalhista e previdenciária, imprimindo nova orientação aos órgãos de fiscalização, no caso do executivo, e posicionando-se mais amplamente contra as fraudes à legislação trabaIhista, nos casos do poder judiciário e do Ministério Público do Trabalho (CARDOSO JÚNIOR, 2009).

Essa mudança no padrão de intervenção do Estado nas áreas trabalhista e previdenciária pode ser creditada a uma reorientação política do governo - como dito, foi reduzida a pressão sindical, indispensável para este tipo de mudança - e também às decisões que buscaram contribuir para o aumento da arrecadação e para o equilíbrio fiscal. 
Quanto às outras formas de inserção, entre 2002 e 2009, desperta a atenção a reduzida contribuição do chamado "setor informal" cujo núcleo é constituído pelos "conta própria" (apenas 10,3\% do incremento da ocupação do período) e pelos trabalhadores "não remunerados" que reduziram de $2,1 \%$ para $1,5 \%$ a sua participação no incremento da ocupação.

Os empregadores - categoria formada em grande parte por pequenos e médios empreendedores - também reduziram o seu peso no estoque de ocupados de $4,5 \%$ pra $4,1 \%$, apesar da retomada do crescimento da economia e da expansão da renda dos segmentos populares ter ampliado consideravelmente o mercado consumidor neste período. Finalmente, o trabalho doméstico manteve a sua participação em torno de 8,7\%, mesmo com a expansão das oportunidades de acesso a um posto de trabalho assalariado no setor privado. Vale ressaltar o fato de que, ao contrário do que se poderia esperar, os percentuais de trabalhadores domésticos na ocupação total são apenas um pouco mais elevados nas RMs nordestinas do que naquelas do sudeste (era de 8\% na RM São Paulo).

Essa sustentação do emprego doméstico numa fase de expansão da economia traduz a persistência de uma oferta excedente de trabalhadores pouco qualificados nos mercados de trabalho metropolitanos; a sustentação da demanda das famílias por este tipo de serviço, pelo fato de não encontrarem, nos serviços públicos, alternativas para o cuidado de crianças, idosos e doentes e, em muitos casos, por não poderem arcar com a compra, no mercado, dos serviços ligados à reprodução realizados pelos trabalhadores domésticos. Também ajuda a explicar a persistência deste espaço do mercado de trabalho, o aumento dos rendimentos reais das famílias, o qual pode ter elevado o universo daquelas que dispõem de recursos para a contratação destes trabalhadores, cada vez mais na condição de diaristas.

\subsection{Distribuição setorial da ocupação}

Outra dimensão importante do comportamento dos mercados de trabalho metropolitanos durante a recuperação é a distribuição setorial das ocupações geradas no período. Conforme citado, a maior parte dos postos de trabalho abertos entre 2002 e 2009 é assalariada e com carteira assinada $(77 \%)$ ou de funcionários públicos (17\%).

O emprego com carteira concentrou-se nos setores do Comércio e reparações e nas Outras atividades - onde estão classificados os serviços prestados a empresas e grande parte das chamadas "terceiras" - e, apenas em terceiro lugar, na Indústria de transformação; Transportes e comunicações, Construção civil, Educação e Alojamento e alimentação aparecem em seguida com participação significativa.

Fora do emprego formal destacam-se, nas regiões metropolitanas, como espaços ocupacionais que se expandem ou se mantêm durante a retomada do crescimento, o serviço doméstico e o trabalho por conta própria, respondendo, cada uma destas posições por cerca de $10 \%$ do incre- 
mento da ocupação entre 2002 e 2009. A expansão dos postos de trabalho por conta própria distribuiu-se entre a Indústria de transformação, Serviços Coletivos, Pessoais e Sociais e outras atividades.

Quando observados simultaneamente o setor de atividade e a posição na ocupação, vê-se que, nos mercados de trabalho metropolitanos, a maior parte dos postos de trabalho está vinculada a atividades do terciário. Nele se constata, em todas as regiões, a forte presença de serviços de baixa produtividade e/ou que se caracterizam por gerar, sobretudo, empregos/ ocupações mal pagos e com menores exigências em termos de qualificação, como é o caso do Comércio, boa parte dos serviços incluídos em Outras atividades, os Serviços Pessoais e de Alojamento e alimentação.

Já a Indústria de transformação, Administração pública e os Serviços de Educação, Saúde e Serviço Social, que tendem a absorver os trabalhadores mais escolarizados, embora também tenham gerado novas vagas, fizeram-no em volume bem menor. Algumas comparações são reveladoras das transformações em curso nos mercados de trabalho metropolitanos. Assim, na média das RMs, os empregos formais gerados no setor do Comércio e reparações somam mais que o dobro daqueles gerados na Indústria de transformação e corresponde a mais de três vezes o número de vagas criadas nos Serviços de Educação, Saúde e Serviços Sociais. Nas regiões do Norte e do Nordeste (exceto Fortaleza) e em Porto Alegre, além da baixa geração de empregos com carteira assinada nos setores que melhor remuneram, verifica-se que os empregos gerados na Indústria de transformação são em número muito inferior ao incremento do número de trabalhadores domésticos (respectivamente 22 mil e 52 mil, na RM Salvador e 4 mil e 37 mil na RM Porto Alegre).

Em síntese, encontrando o seu dinamismo, principalmente na expansão do mercado interno, puxada pela incorporação do segmento de baixa renda ao consumo de massa - sem o suporte de uma política industrial e sem a melhoria da qualidade de serviços estruturantes do bem-estar, como os da educação e da saúde - nos anos 2000 a economia brasileira recuperou a capacidade de geração de empregos. Porém, na maioria dos casos, dentro de um padrão rebaixado, que gera reduzido número de bons empregos (em termos de remuneração, oportunidades de carreira e a qualificação), relativamente aos ganhos de escolaridade das novas gerações. O elevado número de trabalhadores escolarizados e desempregados (em sua maioria, jovens) pode estar, em alguma medida, traduzindo este descolamento entre a qualidade dos postos de trabalho oferecidos e as expectativas de uma parte daqueles que atingiram níveis mais elevados de escolaridade.

\subsection{Rendimentos}

Os dados sobre rendimentos dos ocupados são úteis para uma primeira avaliação da qualidade dos novos postos de trabalho criados nos mercados metropolitanos e este descolamento do nível de escolaridade 
atingido por uma parcela expressiva dos ofertantes de trabalho. Tais dados estão organizados por "classes de rendimento em salários mínimos" o que dificulta a comparação intertemporal no período em que ocorreu uma recuperação do valor real do salário mínimo na ordem de significativos 47,4\%. Com este aumento, distribuído entre 2005 e 2009, o deslocamento de uma classe de renda para outra imediatamente inferior pode ser apenas um efeito estatístico, ou seja, pode não significar redução do rendimento. Isto é verdadeiro, especialmente para as primeiras classes de rendimento da distribuição, cujos intervalos são menores, e menos provável nas últimas classes, cujo intervalo é de cinco salários mínimos ou mais. De qualquer modo, o importante é lembrar que estes dados devem ser tomados apenas como sinalizadores, não servindo para mensurar a real evolução da distribuição dos rendimentos do trabalho, melhor captada com cálculo dos decis e percentis desta distribuição.

Levando em conta esta limitação dos indicadores em uso, serão comentadas apenas as proporções de ocupados com rendimento do trabalho principal abaixo de um salário mínimo e nas duas últimas classes de rendimento (entre 10 e 20 salários mínimos e 20 ou mais salários mínimos) para duas tabulações: a que distribui os ocupados por posição na ocupação e a que os distribui por anos de estudo. Antes, porém se avalia o comportamento da distribuição dos rendimentos para o conjunto dos ocupados nos mercados de trabalho metropolitanos. No incremento do período, cerca de $8 \%$ das ocupações situaram-se na faixa de rendimento de até $1 / 2$ Salário Mínimo (SM) e nada menos do que $37,8 \%$ na faixa de mais de $1 / 2$ a 1 SM, ou seja, um pouco menos da metade $(45,8 \%)$ dos postos de trabalho que surgiram entre 2002 e 2009 nos mercados de trabalho mais dinâmicos, pagavam, no máximo, um salário mínimo.

Mesmo considerando os ganhos reais deste salário, trata-se de postos de trabalho com baixa remuneração e, a depender do perfil do trabalhador - chefe de família, trabalhadores qualificados e/ou com escolaridade mais elevada - pode-se considerá-la baixíssima. Com efeito, apesar dos ganhos reais acumulados por este salário de referência na segunda metade dos anos 2000, em 2009, na data de referência da PNAD, o salário mínimo vigente era de $R \$ 465,00$ e o clássico indicador de salário necessário, calculado pelo Departamento Intersindical de Estatística e Estudos Socioeconômicos (DIEESE) - historicamente utilizado pelos sindicatos na luta pela recuperação dos salários - era de $R \$ 2.065,47$, considerada renda mínima necessária para assegurar o atendimento das necessidades básicas de uma família com dois adultos e duas crianças. Este valor correspondia, em 2009, a 4,4 salários mínimos, patamar atingido apenas por aqueles que se encontravam, naquele ano, na faixa de 3 a 5 salários mínimos de rendimento mensal ou acima dela, os quais somavam, naquele ano, apenas $23,7 \%$ dos ocupados das metrópoles. 
Além disso, quando observada a distribuição por classes de rendimento do incremento da ocupação no período, verifica-se que esta faixa e as superiores foram esvaziadas, isto é, apresentaram saldo negativo, sugerindo que postos de trabalho com tal nível de remuneração foram, em maior quantidade extinguidos do que criados.Colocando o foco nas duas classes de rendimento mais elevadas - acima de 10 SM - vê-se que na média dos mercados de trabalho metropolitanos elas registraram incrementos negativos em todas as posições na ocupação, inclusive no caso dos empregos formais. Segundo Pochmann (2012, p.19), nos anos 2000, no segmento de ocupados "com rendimento acima de três salários mínimos mensais, houve redução no nível de emprego: [...] quase 400 mil postos de trabalho a menos ao ano."

Outro comentário que pode ser feito, a partir dos dados de renda por posição na ocupação, é que, apesar das importantes diferenças entre estas posições em termos de proteção social, representando a baixa qualidade dos postos de trabalho existentes no mercado brasileiro, os rendimentos modais das diversas posições na ocupação são muito próximos, com exceção das posições de funcionário público e de empregador. Tanto em 2002 como em 2009 a moda das distribuições de renda cai, para a maioria, na faixa de 1 a 2 salários mínimos: $(34,6 \%$ dos empregados com carteira no início do período e $47,3 \%$ no final; $34,3 \%$ e $37,5 \%$ dos empregados sem carteira e $25 \%$ e $28,3 \%$ dos conta própria). A classe modal para os trabalhadores domésticos, que também era de 1 a 2 SM em 2002 (38,6\%), passou a ser a classe imediatamente inferior em 2009, mais de $1 / 2$ a 1 SM $(39,3)$. Tal concentração de ocupados na faixa de rendimento que contém o salário mínimo explica o impacto extremamente positivo da política de reajuste deste salário sobre os rendimentos dos trabalhadores mais pobres. Somada à formalização dos vínculos - que contribui para ampliar o número de trabalhadores que recebem o salário mínimo - constituem as duas mudanças de maior impacto sobre os mercados de trabalho metropolitanos nos anos 2000.

A observação da evolução da distribuição dos rendimentos por anos de estudo apresenta um resultado coerente com o anterior. As classes de rendimento mais elevadas - mais de 10 salários mínimos - se esvaziam até a faixa de escolaridade equivalente ao ensino médio (11 a 15 anos de estudo), apresentando saldo positivo na classe de 10 a 20 SM, apenas para os que têm formação de nível superior (15 ou mais anos de estudo). A constatação da distribuição do incremento da ocupação por renda e escolaridade é elucidativa dos movimentos do mercado de trabalho entre 2002 e 2009. Enquanto o contingente de ocupados deslocava-se da esquerda para a direita, em direção às classes de escolaridade mais elevada, na distribuição por classes de salário mínimo ocorria o contrário, aumentando a frequência nas classes de rendimento mais baixo. 
Como consequência destas tendências contrárias - mais escolaridade e menor rendimento - em 2009, até a faixa de 11 a 14 anos de estudo (ensino médio completo) a mediana da distribuição dos rendimentos situava-se na classe de 1 a 2 SM e apenas para os que tinham mais de 15 anos de estudo a mediana chegava à faixa de 5 a 10 salários. Este indicador é coerente com os rendimentos médios por anos de estudo, que em todos os mercados metropolitanos mostram que os portadores de diploma de nível superior auferem rendimentos bem superiores aos que não os possuem, indicando que este título ainda tem um valor de mercado significativo, ocorrendo o contrário com o certificado do ensino médio. Note-se, no entanto, que em 2009, eram bastante elevadas as proporções de ocupados com ensino médio ou superior completo nas classes de rendimento mais baixas. Assim, nada menos que 35,5\% dos trabalhadores com formação universitária ganhavam, no máximo, 3 SM e 23,7\% até 2 SM. Entre os que tinham ensino médio completo/superior incompleto 79,7\% ganhavam até 3 SM e 63\%, no máximo, 2 SM.

\section{Considerações finais}

Em síntese, os mercados de trabalho metropolitanos registraram uma vigorosa recuperação nos anos 2000, invertendo a tendência da década anterior ao desassalariamento e à precarização dos vínculos, como efeito da retomada do crescimento da economia e de uma intervenção do Estado, focalizada na ampliação dos rendimentos dos mais pobres e no aumento da arrecadação, inclusive através da maior fiscalização do cumprimento das legislações trabalhista e previdenciária. Tal política alcançou êxito no que se refere à redução das desigualdades entre os que vivem com rendimentos do trabalho, mormente em decorrência dos ganhos reais dos ocupados situados da base da pirâmide, uma vez que os trabalhadores situados nas classes de rendimento mais elevadas, se muito, mantiveram o seu poder de compra.

Ademais, viu-se que os ganhos de escolaridade da população, particularmente dos mais jovens, propiciaram aos empregadores a oportunidade de contratação de trabalhadores com escolaridade média bem superior à de gerações passadas, embora a retomada do crescimento esteja evidenciando a existência de déficits de trabalhadores com as qualificações específicas exigidas pelos setores de atividade em expansão.

Constatou-se que a escolaridade crescente dos trabalhadores vem acompanhada de uma tendência à desvalorização dos diplomas - em especial o do ensino médio - preservando-se ainda a vantagem relativa do nível universitário, embora já não seja suficiente para assegurar um posto de trabalho e, menos ainda, para garantir a todos os diplomados que chegam 


\section{Revistg all pgutg}

\} O EMPREGO NO BRASIL URBANO NOS ANOS 2000 - BORGES, A. M. C. \}

ao mercado de trabalho, rendimentos correspondentes ao padrão de vida deste segmento na geração anterior.

A expansão recente do emprego formal está concentrada no setor terciário, em especial em algumas atividades que pagam salários mais baixos. A expansão do emprego nos setores com produtividade mais elevada como a indústria de transformação - ou que exige escolaridade elevada foi menos significativa, o que deve explicar o grande número de trabalhadores com escolarização média e superior em postos de trabalho com remuneração nas faixas de rendimento entre 1 e 3 SM.

Finalmente, conclui-se pela necessidade de recuperar ou definir parâmetros mais claros para a avaliação das mudanças em curso no mercado de trabalho brasileiro, pois os indicadores até aqui utilizados para avaliar, por exemplo, a qualidade do emprego - com destaque para a posição na ocupação - já não dão conta desta dimensão dos postos de trabalho. Neste sentido, é grande a expectativa dos pesquisadores do mercado de trabalho com relação à nova Pesquisa Nacional por Amostra de Domicílios (PNAD - IBGE), que incorpora outras variáveis, contribuindo para avançar o debate sobre o mercado de trabalho, as novas formas de trabalho e as novas e veIhas relações de trabalho. 


\section{Revistg Q PII paUtg}

\} O EMPREGO NO BRASIL URBANO NOS ANOS 2000 - BORGES, A. M. C. \}

\section{Referências}

BORGES, Ângela. Desestruturação do mercado de trabalho e vulnerabilidade social: a Região Metropolitana de Salvador na década de 90. Tese [Doutorado em Sociologia]. Salvador: UFBA, 2003.

. Mercado de trabalho da RMS: duas décadas de transformações. Bahia Análise \& Dados, v. 21, p. 399-416, 2011.

CARDOSO JUNIOR, J.C.. Determinantes da recuperação do emprego formal no Brasil: evidências para o período 2001/2005 e hipóteses para uma agenda de pesquisa. Revista de Economia Política, v. 29, n. 4, p. 357-376, out./ dez. 2009.

GONÇALVES, R. Redução da desigualdade de renda no governo Lula; análise comparativa, jun., 2011 Disponível em: <http://www.socialismo.org.br/porta l/economia-e-infra-estrutura/101-artigo/2104-botando-o-pingo-no-i.> Acesso em: 01 set. de 2011.

INSTITUTO DE PESQUISA ECONÔMICA APLICADA. Emprego e oferta qualificada de mão-de-obra no Brasil: projeções para 2011. n. 89. Brasília: IPEA, abr. 2011. (Comunicados do IPEA, 89).

POCHMANN, M. Estrutura social no Brasil: mudanças recentes. Serviço Social e Sociedade, SP, n. 104, p. 637-649, out. / dez. 2010.

. Nova classe média? O trabalho na base da pirâmide social brasileira, São Paulo: Boitempo, 2012.

Recebido em 27 de setembro de 2012.

Aprovado para publicação em 31 de outubro de 2012. 